\title{
A participação autogestora e o cancelamento da subsunção real do trabalho ao capital
}

\author{
Vilma Margarete Simão \\ Universidade Regional de Blumenau (FURB)
}

\section{A participação autogestora e o cancelamento da subsunção real do trabalho ao capital}

Resumo: O artigo aborda as influências das trajetórias ocupacionais na formação de grupos de associados e na gestão do trabalho cooperado, a partir de três experiências de cooperativas de produção, localizadas em cidades industrializadas do estado de Santa Catarina. Para a análise, utiliza-se da categoria de participação autogestora e da leitura marxiana acerca da categoria de superpopulação relativa, trabalhador coletivo e subsunção real do trabalho. A análise longitudinal mostra que, nas trajetórias ocupacionais, é presente o evento de desemprego e de não inserção no mercado de trabalho, e que, motivados por eventos externos, os trabalhadores mudam da condição de integrantes da superpopulação relativa para associados de cooperativas de produção. Quanto à organização do trabalho, há tendência para a reprodução da experiência já vivida na empresa empregadora.

Palavras-chave: trajetória, subsunção real, divisão do trabalho, participação autogestora.

\section{Self-managed Participation and the Cancelation of the Real Subsumption of Labor in Capital}

Abstract: This articles analyzes the influences of the occupational trajectories in the formation of membership groups and on the management of cooperative labor, based on three experiences with productive cooperatives located in industrialized cities of Santa Catarina. The analysis used the category of self-managed participation and a Marxian reading of the category of relative surpluspopulation, collective labor and real subsumption of labor. The longitudinal analysis showed that in occupational trajectories, the event of unemployment is present, as well as non-insertion in the labor market, and that, motivated by outside events, workers change their condition from members of the relative surplus-population to members of productive cooperatives. Concerning the organization of labor, there is a trend toward the reproduction of the experience in the employing company.

Key words: trajectory, real subsumption, division of labor, self-managed participation. 


\section{Introdução}

É bastante incomum, através da renda obtida por meio de salário, o trabalhador fazer reservas e, com o ato de poupar, adquirir meios de produção e se libertar da alienação do resultado de seu trabalho. Mas, apesar de incomum, na última década, dadas as proporções do desemprego e de processos falimentares ocorridos no Brasil, trabalhadores vieram a se associar a unidades coletivas de trabalho. O objetivo dessas iniciativas era transformar o trabalho excedente em parte da contribuição individual na construção da riqueza do coletivo dos trabalhadores, de forma cooperada e autogestora. O capital, como resultado da apropriação do excedente do trabalho, por um proprietário dos meios de produção, não mais existiria e, assim, estaria cancelada a subsunção real do trabalho no capital.

O trabalhador com condições objetivas de trabalho (meios de produção) e com condições subjetivas de trabalho (meios de subsistência), possibilitado pelo coletivo do grupo, que veio a constituir uma unidade coletiva de trabalho (cooperativa), não se estabelece como proprietário. Além disso, não há um capital que se lhe oponha como capital, assim como as condições de trabalho não se opõem como propriedade alheia; ou seja, não há, pela própria constituição jurídica da unidade/cooperativa, a subsunção real do trabalho no capital.

Conferindo a possibilidade histórica de rompimento da subsunção real do trabalho ao capital, este artigo apresenta três experiências de cooperativas constituídas e geridas por trabalhadores associados. São elas ${ }^{1}$ :

Cooperativa de Retífica de Motores a Diesel (Redimcooper), com sede na cidade de Blumenau. Em 1997, 21 trabalhadores assalariados adquiriram o maquinário do ex-patrão e continuaram a prestar serviço de retífica. Sua clientela emana das regiões do Alto Vale e do Vale do Itajaí, totalizando 43 cidades. Cooperativa do Sul (Coopersul), com sede em Criciúma. Em 1999, 106 trabalhadores assalariados assumiram a gestão da empresa do ex-patrão em situação de falência e continuaram produzindo peças de reposição para indústrias dos ramos siderúrgico, metalúrgico e mineral do Brasil e América Latina. Atualmente, a cooperativa posiciona-se no cenário nacional, no segmento em que atua, entre as 10 principais fábricas do setor. Cooperativa Amiga do Meio Ambiente (Cooperama), com sede em Joinville. Em 2005, um grupo de pessoas, com uma trajetória de vulnerabilidade social, passou a integrar o projeto social de trabalho e renda desenvolvido pela organização não governamental (ONG) denominada Consulado da Mulher. Com o apoio financeiro e permanente assessoria técnica de funcionários da $\mathrm{ONG}$, nove pessoas organizaram uma cooperativa de classificação de materiais descartados como lixo. A área de atuação da cooperativa é restrita à cidade na qual está localizada a sede da unidade de trabalho.

Se, durante a trajetória ocupacional das três experiências de cooperativas, o que diferenciava o grupo dos excluídos era a não composição do trabalhador coletivo, hoje, com a organização de cooperativas de produção, essa diferenciação foi superada. As influências dessas trajetórias ocupacionais no processo de constituição das cooperativas e a organização do trabalho cooperado e autogestor, nos aspectos da divisão e gestão do trabalho, são resumidamente apresentadas neste artigo.

\section{Metodologia}

A discussão exposta neste artigo tem como fonte a tese de doutoramento, apresentada ao programa de Política Social da UnB em 2008 (SIMÃO, 2008). Trata-se de um estudo de caso comparativo, de caráter longitudinal, estruturado a partir de uma pesquisa qualitativa, e fundamentado em material coletado pelos instrumentos de entrevista semiestruturada, questionário longitudinal, bibliográfico e documental. $\mathrm{O}$ universo da pesquisa são as cooperativas de produção - cooperativas que comercializam o objeto de seu trabalho e não a força de trabalho em si mesma - localizadas em cidades industrializadas do Estado de Santa Catarina. Para a delimitação da amostra, foram adotados os seguintes critérios: a) cooperativas compostas por grupos de trabalhadores com trajetórias ocupacionais diferenciadas; b) trajetória diferente no percurso de constituição do grupo de pessoas que viria a compor o quadro de associados da cooperativa; c) cooperativas do tipo produção, ou seja, unidades de trabalho com a presença da cooperação próxima aos preceitos do trabalhador coletivo; d) inclusão, pelo mapeamento Empreendimento Econômico Solidário (EES) realizado pela Secretaria Nacional de Economia Solidária (SENAES), que tratava de uma unidade de trabalho cooperativada e autogestora. A partir desses critérios, ficaram delimitadas três cooperativas: uma do setor secundário e duas do setor terciário.

O objetivo central do estudo é demonstrar e explicitar a influência das trajetórias ocupacionais no processo de constituição das cooperativas incluídas na amostra e, por sua vez, a influência dessa trajetória na organização e gestão nas unidades coletivas de trabalho. Para a concretização do objetivo, buscou-se desvelar as mediações das trajetórias ocupacionais na constituição e na organização do trabalho e comparou-se o processo de constituição aos procedimentos na organização e gestão do processo de trabalho, bem como a presença da participação autogestora e o cancelamento da subsunção real do trabalho ao capital. 


\section{A influência das trajetórias na composição do grupo de trabalhadores associados}

A análise das trajetórias ocupacionais, aqui apresentada, fundamenta-se na categoria de superpopulação relativa de Karl Marx, a qual será rapidamente apreciada.

Marx, ao analisar a situação de trabalho, no que ele denomina de superpopulação relativa (aquela que fica entre a condição de ocupados ou de não ocupados), diz que ela existe sob as mais variadas nuances: "[...] todo trabalhador dela faz parte durante o tempo em que está desempregado ou parcialmente empregado" (MARX, 2005b, p. 744). Esses matizes aparecem mais ou menos acentuados nas fases alternadas do ciclo industrial. Segundo o autor, há três formas principais de superpopulação relativa, que se reproduzem periodicamente: flutuante, latente e estagnada. Essas três formas estão continuamente presentes entre a população relativa, mas isso não significa total isenção da população ativa a situações típicas da superpopulação relativa. Contudo, pela qualidade da capacidade de trabalho dessa população relativa, ela está mais sujeita a permanecer nessas condições de instabilidade, ou, até mesmo, de exclusão permanente da empregabilidade de sua força de trabalho. Outro protótipo é o estrato da superpopulação relativa dos inaptos para o trabalho em decorrência da falta de capacidade de adaptação, por consequência, da divisão de trabalho. Essa categoria se diferencia das outras três porque a situação de relatividade é uma constante. Nessa categoria, podem ser incluídos os desempregados estruturais, os excluídos do mercado de trabalho pela condição de desqualificados perante as novas exigências do mercado, e os desempregados com idade não mais empregável.

A partir da análise de Marx da categoria de superpopulação relativa, é possível distinguir a população trabalhadora, na linguagem de trajetórias ${ }^{2}$ ocupacionais, em dois tipos de categorias: população com vínculo de assalariamento contínuo e superpopulação relativa. Na primeira categoria está o trabalhador pertencente à população empregada, em uma trajetória ocupacional ascendente, em situação de emprego estável e em contínua melhoria profissional e de renda. A seguir, encontra-se o trabalhador com uma trajetória ocupacional regular e estável, em situação de emprego estável, mas sem melhorias de seus rendimentos por decorrência de melhor capacitação de sua força de trabalho. Esse tipo aproxima-se do protótipo de superpopulação relativa estagnada.

Quanto aos estratos da superpopulação relativa, sem vínculo de assalariamento contínuo, na linguagem de trajetórias ocupacionais, distinguem-se os três tipos a seguir. a) o trabalhador com trajetória ocupacional regular e descendente, que pode ser dispensado concomitantemente ao avanço tecnológico, aproximando-se do padrão da superpopulação latente. Nesse tipo de trajetória, há tendência para a acomodação (não atualização dos conhecimentos, estagnação da capacidade de trabalho) e posterior inadaptação às novas exigências da divisão técnica do trabalho.

b) o trabalhador com trajetória ocupacional irregular e vulnerável, com períodos longos e muito longos na condição de desempregado;

c) e, por último, os inaptos para a divisão do trabalho capitalista, aqui denominada trajetória de exclusão da composição do trabalhador coletivo.

Entende-se que o trabalhador coletivo, segundo Marx (2005b), constitui-se de muitos trabalhadores parciais que estão em condições materiais para desenvolver o processo de trabalho de forma cooperada e, no caso capitalista, forçada pelo capital.

Os trabalhadores, que constituíram as três cooperativas de produção em análise, fizeram parte da superpopulação relativa, visto que, nas trajetórias ocupacionais, estiveram presentes os eventos de desemprego, de parcialmente empregado e de não inserção no mercado de trabalho. Desse modo, na caracterização das trajetórias ocupacionais dos associados de tais cooperativas de produção, identificaramse três tipos: uma trajetória ocupacional assalariada regular a estável, itinerário dos sócios da Redimcooper; uma trajetória regular e irregular vulnerável, percurso assalariado dos sócios da Coopersul; e a ausência de trajetória ocupacional assalariada e a exclusão da composição do trabalhador coletivo, trajeto dos sócios da Cooperama. Nenhuma dessas trajetórias foi promissora no sentido de lhes possibilitar uma poupança.

Para esses trabalhadores associados, com uma trajetória ocupacional muito própria da superpopulação relativa, a adesão ao modelo de trabalho cooperativado foi motivada pelas dificuldades de emprego. Portanto, eles foram induzidos a constituir uma cooperativa de produção por eventos externos à decisão do próprio grupo.

Então, muito embora a trajetória ocupacional, anterior ao evento de constituição da cooperativa, tenha mediado o modo de organizar e gerir a unidade de trabalho cooperado, o último evento nessa trajetória também traz desdobramentos na organização e na gestão do trabalho cooperado.

A trajetória de exclusão da composição do trabalhador coletivo e, até mesmo, de outras relações de trabalho assalariado, bem como a necessidade humana de autonomia não satisfeita no decorrer da trajetória dos sócios da Cooperama, foram determinantes para a presença dos eventos, próprios da superpo- 
pulação relativa dos relativamente "aptos" (trabalhar em atividades dispensadas pelos outros estratos da superpopulação relativa) e dos "inaptos" para o trabalho na indústria.

No processo de formação da Cooperama, o evento inicial diferencia-se das outras experiências analisadas. A trajetória dos cooperados carece de eventos de rompimento do vínculo assalariado: uns não tiveram tal vínculo, e os que o possuem mantiveramse empregados porque o rendimento da cooperativa inviabiliza dispensar outras atividades remuneradas. Todavia, o grupo de sócios é constituído, em sua maioria, por pessoas com trajetórias ocupacionais sem a presença da composição do trabalhador coletivo, e alguns nem mesmo tiveram vínculo empregatício formal ou informal. São, em geral, sem qualificação para o trabalho assalariado. Assim, estavam propensos a se tornarem usuários de projetos sociais desenvolvidos por ONGs e a determinados programas, onde ficariam sujeitos aos critérios próprios de inclusão das organizações. No caso do grupo que constituiu a unidade de trabalho Cooperama, o acesso ao projeto sócioeducativo direcionado aos seus filhos estava condicionado a uma contrapartida dos pais, a qual se concretizava com a inserção deles em atividades comunitárias. A atividade decidida pelo grupo foi a organização de uma horta comunitária e esse mesmo grupo foi interpelado por outra ONG, denominada Consulado da Mulher ${ }^{3}$, para organizar uma cooperativa de trabalho. Portanto, a organização da unidade de trabalho Cooperama teve seu início mediado pela precisão da assistência social para suprir necessidades humanas básicas.

A consecução das condições objetivas de trabalho foi possível por ações de autoajuda, de ajuda filantrópica e de solidariedade. Contudo, a autonomia no grupo vai sendo conquistada à medida que o próprio trabalho vai possibilitando aumento do rendimento da cooperativa, a ponto de essa cooperativa adquirir um terreno e construir sede própria. Nesse ponto, a Cooperama assemelha-se a outras experiências em que a labuta coletiva foi o principal propiciador de aquisição de meios de trabalho. Seu maior bem é o trabalho e conta com sua própria força e capacidade de trabalho para manter e desenvolver uma unidade de trabalho autogestor.

Conforme já citado, o processo de formação da Cooperama diferencia-se das outras experiências aqui analisadas. Por influência da própria trajetória ocupacional, para análise do processo de formação da Coopersul e da Redimcooper, é utilizada a categoria marxiana de subsunção. E para melhor compreensão analítica, rapidamente é apresentado o que Karl Marx entende por tal categoria.

$\mathrm{O}$ autor denomina como subsunção do trabalho no capital a conversão do processo de trabalho em instrumento do processo de valorização ou de autovalorização do capital: da criação de mais valia. Neste processo, o capitalista é o dirigente, guiando a exploração do trabalho alheio. Portanto, "o que, desde o início, distingue o processo de trabalho subsumido, [...] é a 'escala' em que se efetua; o mesmo é dizer, por um lado, a vastidão dos meios de produção adiantados e, por outro, a quantidade de operários dirigidos pelo mesmo patrão" (MARX, 2004, p. 90). Todavia, Karl Marx distingue dois tipos de subsunção do trabalho no capital: a formal e a real. A formal, por se submeter a um processo de trabalho pré-existente (MARX, 2004, p. 90). Então, a subsunção formal existe quando "[...] só se pode produzir mais valia recorrendo ao 'prolongamento do tempo de trabalho, quer dizer, sob a forma da mais valia absoluta' [...]" (MARX, 2004, p. 88-89). Já a subsunção real do trabalho no capital decorre das condições desenvolvidas na sociedade capitalista para extração da mais valia relativa, com diminuição do tempo de trabalho necessário para a produção de uma coisa e para reduzir o valor da força de trabalho (MARX, 2005a, p. 366). Nesse sentido, as duas formas da mais valia, a absoluta e a relativa, correspondem a duas formas da subsunção do trabalho no capital, ou a duas formas da produção capitalista, das quais a primeira precede sempre a segunda. Porém, a subsunção real só veio a existir no modo de produção propriamente capitalista, onde os produtores perdem a "autonomia" no processo de produção e passam, na condição de assalariados, a uma relação de "hegemonia e subordinação" ao capital.

Feito tal esclarecimento, pode-se verificar como os associados da Coopersul e da Redimcooper vêm rompendo com a subsunção do trabalho no capital, no processo de organização da cooperativa e no modo como instituem a gestão autônoma.

No processo de formação da Coopersul, o evento inicial foi o atraso no pagamento dos salários pelos ex-patrões, ou seja, a elevada subsunção levou os trabalhadores a exigir sua participação na gestão para tentar garantir o pagamento de seus direitos trabalhistas. Depois de uma trajetória conflituosa com os ex-patrões, com o apoio do Sindicato dos Metalúrgicos, em janeiro de 1999, a ação dos trabalhadores consegue o arrendamento do parque fabril da empresa em situação de falência. Assim, os empregados assumiram a empresa e constituíram a Coopersul com a formação de um grupo de produtores associados. Com o evento da cogestão, os associados obtiveram informações e conhecimento possibilitadores de autonomia na gestão da empresa dos ex-patrões. Nessa cooperativa, o critério de associação foi o engajamento dos trabalhadores pelo controle da cogestão, coordenado pelo sindicato. Todavia, de certo modo, o grupo já estava formado, pois, a princípio, todo empregado da empresa 
em processo de falência poderia permanecer na empresa transformada em cooperativa de trabalho.

Os trabalhadores, com a criação da Coopersul, romperam com a subsunção real ao capital e instituíram uma gestão onde os funcionários são associados e, como tal, têm o poder de participar nos rumos da cooperativa. Contudo, a trajetória de constituição foi conflituosa e instável, principalmente, pela ameaça de concretização do evento sucessão ${ }^{4}$, resultando em fragilidade do vínculo societário e até mesmo em desligamento de associados.

No caso da Redimcooper, o evento de fechamento da Retífica AG ocorreu sem a presença de dívidas trabalhistas e, no desligamento da condição de assalariados da retífica, os trabalhadores acessaram aos recursos do FGTS e receberam as devidas indenizações. Como a empresa em que trabalhavam ia encerrar as atividades e todos seriam demitidos, um grupo dos futuros desempregados reuniu-se e comprou o maquinário, por sugestão e financiamento do patrão. Na reunião, esse grupo, apesar de somar mais do que o mínimo necessário exigido por lei para a formação de uma cooperativa (21 membros), teve relativa liberdade de escolha quanto à nova equipe de trabalho a ser formada, sendo um dos sócios imposto pelo expatrão. Tal associado deveria permanecer na cooperativa até o final do pagamento do financiamento das máquinas. Dos 21 sócios-fundadores da Retimcooper, com exceção daquele imposto pelo ex-patrão, todos continuam trabalhando na cooperativa e, por decisão do coletivo, não mais querem incluir novos sócios, apenas preencheram a vaga daquele que se desligou após o término do pagamento do financiamento. Essa decisão, tomada por eles, foi sustentada pela ideia de que os sócios produtores devem ter um mesmo valor nas retiradas e não consideram justo um novo associado que não passou pelos sacrifícios do processo de constituição de uma unidade de trabalho - fazer jus a uma retirada igual a dos fundadores.

Portanto, a iniciativa de montar uma cooperativa foi sugerida e financiada pelo ex-patrão, o que, para ele, foi um bom ‘negócio' que em nada diminuiu seu capital, pois, além de não precisar pagar encargos indenizatórios do processo de demissão, ainda vendeu o maquinário (venda parcelada em 60 meses) para os seus ex-empregados.

\section{A reprodução da divisão hierárquica do trabalho}

Na Coopersul e na Redimcooper, há uma tendência para a manutenção da organização do trabalho, no concernente à divisão e definição das funções e dos critérios de ocupação, já aplicada pelos seus expatrões. E, na Cooperama, os associados apresentam dificuldades de entender a divisão do trabalho como forma de organização do próprio trabalho e, nem por isso, menos cooperado ou solidário.

$\mathrm{Na}$ Cooperama, observa-se uma organização do trabalho ajustada ao tempo disponível de cada cooperado. Quando o associado chegava à sede da cooperativa, desenvolvia um trabalho necessário e que ninguém estivesse desenvolvendo; à medida que o tempo foi passando, as funções foram se cristalizando. Então, tal critério de organização não foi pensado e decidido no coletivo, pois foi ocorrendo na prática cotidiana e, por isso, pode ser considerado como uma divisão espontânea. A divisão espontânea é também decorrente do fato de inexistir uma rígida jornada de trabalho, já que cada sócio dedica à unidade coletiva de trabalho a quantidade de tempo livre de que dispõe.

Como não há igualdade de tempo dedicado ao trabalho da cooperativa, as repartições mensais individuais, resultantes do trabalho coletivo, seguem o critério do tempo trabalhado, sendo desconsideradas impossibilidades temporárias de participação de cotatrabalho. Desse modo, é reproduzido o direito burguês que não adota o critério de participação e distribuição da riqueza de acordo com as capacidades e necessidades das pessoas. Todavia, o direito burguês também orienta os critérios de repartições nas outras duas experiências aqui analisadas.

Outra característica na Cooperama refere-se ao cargo de presidente, que é eleito e passa a ocupar a função de administrador da cooperativa. Mesmo nessa função, nada impediria ao presidente de participar na produção e seleção de materiais, além de também coordenar os trabalhos da cooperativa. A atuação do presidente vem sendo questionada, apesar das críticas não estarem direcionadas à divisão do trabalho, que separa o administrativo do produtivo, mas sim à falta de democracia na tomada de decisões, como por exemplo, a escolha do substituto para desempenhar suas funções em sua ausência. O questionamento é sobre a ausência de democracia nessa decisão e não a separação entre o trabalho administrativo e o produtivo, ou, nas palavras deles, trabalho "sujo" (separação dos materiais recicláveis ou reutilizáveis) e trabalho "limpo" (compra e venda dos materiais).

O exercício do poder autônomo e coletivo na Cooperama também vem sendo obstaculizado pelo tempo de trabalho dedicado à unidade, porque a cotatrabalho tem sido colocada como sustentáculo de ampliação de exercício do poder. Na opinião daqueles que dedicam tempo integral, o administrador também deve ter dedicação exclusiva às atividades da Cooperama.

Por outro, naquela cooperativa, há manifestações de entendimento do trabalho cooperativado como aquele com ausência de divisão do trabalho. Até parece que, quanto menor o conhecimento acumulado 
pela prática da cooperação própria do trabalhador coletivo, maior é a dificuldade de entender as exigências da divisão do trabalho. Por outro lado, a divisão do trabalho não precisa seguir o modelo taylorista, que separa os pensantes dos não pensantes, aqueles com poder de mando daqueles que obedecem, ou ainda, as divisões capitalistas onde há separação entre o proprietário dos meios de produção e aqueles que colocam em ação esses meios.

Já na Coopersul, que manteve a mesma divisão de trabalho de antes de se estruturar, cada um continuou desenvolvendo as mesmas tarefas anteriores, com exceção de dois ou três que passaram a fazer parte da diretoria. A pessoa indicada para presidir a cooperativa era empregada da empresa falida, mas estava licenciada para atuar na função de presidente do sindicato da categoria, e o vice-presidente já ocupava cargo diretivo na empresa falida. Apenas três pessoas alteraram as funções antes exercidas e foi mantida a hierarquização no controle do trabalho, persistindo cargos de gerência do tipo: supervisor geral e de setor, supervisores e líder de equipe (mantida até mesmo a terminologia utilizada pelos ex-patrões). Esses cargos de concepção ou de controle de trabalho são ocupados por sóciosfundadores. Assim, o processo de trabalho é pensado, organizado e controlado pelo grupo de associados fundadores da Coopersul. Portanto, a organização do trabalho implantada na Coopersul nega aos trabalhadores a compreensão e a autodeterminação no processo de trabalho e de seus objetivos, e separa a concepção da execução.

Na cooperação voluntária, é desnecessário o controle hierárquico do trabalho. Para tanto, não basta a superação da propriedade privada dos meios de produção. Também não basta a superação da divisão técnica do trabalho, mas já é um começo para novas bases da cooperação. Isso implica o estabelecimento dos parâmetros da produção requerida para manter a fábrica em funcionamento e seus produtores com condições de satisfazer suas necessidades para além da simples reprodução da força de trabalho.

Quando há presença de um poder autônomo de decisão, há o exercício de gestão, de modo que se pode agir sobre a política da empresa ou sobre suas possibilidades de sobrevivência e de desenvolvimento. E, com a presença desse tipo de poder, desnecessária se faz a manutenção de gerentes, supervisores e líderes controladores. É evidente que esse tipo de poder pressupõe a cooperação, e esta será coordenada de acordo com a disposição exigida pela própria complexidade da organização do trabalho e por suas respectivas divisões de tarefas. Entretanto, se todos se sentem pertencentes e o resultado do trabalho coletivo for desfrutado por todos de forma igualitária ou, no mínimo, muito semelhante, não se faz necessário um controle gerencial do tipo capitalista.
Não é necessária a rejeição da repartição de tarefas em funções; elas são próprias da organização onde há a presença do trabalhador coletivo, e em nada impossibilitam o exercício do poder autônomo do coletivo, resultante de uma participação autogestora ${ }^{5}$ que faz a diferença.

A divisão do trabalho executada na Coopersul, também comum nas empresas capitalistas, nega aos trabalhadores a compreensão e a autodeterminação no processo de trabalho e de seus objetivos, e separa o processo de decisão e concepção da execução.

Outra mediação da trajetória ocupacional dos associados e da trajetória de constituição da Coopersul é a não superação, ou pelo menos tentativa, da alienação do resultado. Há uma remuneração fixa independente do resultado. Em época de crise, é até preferível para um trabalhador receber o seu rendimento independentemente das condições da empresa. Porém, quando se trata de uma cooperativa de trabalho, onde todos são os seus produtores, pela própria condição de coproprietários dos meios de produção e da inexistência de assalariamento, a definição dos valores das repartições dependerá do desempenho da unidade de trabalho. Contudo, não se pode almejar a manutenção ou o desenvolvimento de uma cooperativa à custa da não satisfação das necessidades humanas dos trabalhadores produtores, para além da simples reprodução da força de trabalho. Lembrando os escritos de Marx, qualquer capitalista almeja a menor remuneração possível ao seu empregado e o máximo de mais valor, possibilitando a subsunção real do trabalho no capital.

Na trajetória da Coopersul, também está presente a manutenção das mesmas pessoas nos cargos eletivos. Essa permanência tem, pelo menos, duas mediações: pequena participação do coletivo dos cooperados nas decisões das políticas de gestão da cooperativa e, portanto, sua não capacitação para assumir a direção da cooperativa e para a existência de canais de participação limitados às exigências legais. Hoje, a Coopersul tem um número de cooperados $60 \%$ mais elevado do que no momento de sua constituição. São 171 cooperados; os conselhos agregam 17 cooperados (incluindo também os suplentes); assim, 10\% integram os conselhos administrativo, deliberativo e fiscal. Não é um percentual desconsiderável, contudo, esses representantes não se organizam junto aos seus representados para discutir, previamente, os assuntos levados aos conselhos. Quanto mais ampliados os espaços de participação, maior será o autocontrole e a possibilidade de construção da autonomia individual e coletiva.

Na Redimcooper, diferentes são as trajetórias ocupacionais dos cooperados e a sua própria trajetória de constituição. Tais trajetórias possibilitaram a organização do trabalho sustentada na cooperação, com uma coordenação aceita por todos os sócios e 
com clareza do coordenador de que sua função não é de chefe ou patrão. Com uma constituição participativa, criaram bases para uma gestão com participação autogestora, em que o poder é exercido coletivamente.

$\mathrm{Na}$ radicalização da autogestão, com participação autogestora, é conveniente a superação do trabalho alienado, tanto no seu processo quanto no seu resultado, bem como a transparência e a precisão das informações em todas as suas instâncias e o sentimento de pertencimento ao coletivo. Essa radicalização vem sendo construída pelo grupo de mecânicos da oficina de retífica. Foram rompidas as representações de patrão e de empregado para aqueles cooperados, os quais redescobriram as suas possibilidades de autonomia e criatividade, e reconheceram sua condição de sujeito, identificando no outro a mesma condição. São trabalhadores aptos para cooperar voluntária e conscientemente, mas ainda restritos ao objetivo comum do grupo de cooperar, pois não há neles a preocupação e a ação solidária com outras iniciativas de trabalhadores. Pode-se dizer que, na Redimcooper, há um poder pertencente ao grupo, que age de comum acordo, dispensando a necessidade de um governo para determinar a melhor ação; há autogoverno, instituído com uma participação autogestora.

$\mathrm{Na}$ organização do processo de trabalho da Redimcooper, todos os associados tinham clareza de qual era a especialidade de cada um e de qual era a participação de uma tarefa no desempenho da tarefa do outro. Tinham um conhecimento acumulado pela trajetória ocupacional ou pelo conhecimento técnico das etapas necessárias para a efetivação de um dado resultado. Até pela própria formação, a cooperação é facilitada, mas, além disso, há vontade de um cooperar com o trabalho do outro, e eles sabem que, quanto maior a cooperação entre eles, melhor será o desempenho da Redimcooper, o que resultará em melhorias nas retiradas individuais mensais. Quanto às repartições, todos recebem o mesmo valor nas retiradas mensais, exceto o presidente, investido da função de coordenador, que recebe $10 \%$ a mais; e, no final de cada ano, são distribuídas as sobras de forma igualitária.

É certo que a facilitação na organização do trabalho também adveio da experiência do último emprego, onde o trabalhador coletivo já estava constituído. Não se pode negar certa reprodução, na distribuição de tarefas, na divisão estabelecida pelos expatrões, apesar da nova composição de não ter sido de todo o grupo anterior. Promoveram-se adequações, mas não se reproduziu a distribuição hierárquica tipicamente capitalista. Quanto aos trajetos do cotidiano e às políticas financeiras e administrativas da cooperativa, há liberdade para todos participarem do debate e da decisão. Pode-se afirmar que, na Redimcooper, vem sendo constituído o poder autônomo, cujo exercício é reagir sobre a política da empresa ou sobre suas possibilidades de sobrevivência e de desenvolvimento.

\section{Considerações finais}

Das experiências analisadas, a Coopersul se destaca pela manutenção da organização do trabalho, sustentada na divisão hierárquica, onde o controle do trabalho é desenvolvido pelos sócios-fundadores. É compreensível o fato de muitos eventos interferirem na organização e na gestão do trabalho autônomo e cooperado; mas, depois de oito anos de existência, já era possível, minimamente, maior diferenciação em relação aos modelos de organização do trabalho, muito próprios da divisão hierárquica capitalista. $\mathrm{O}$ que se verifica é mais uma trajetória de reprodução das relações vividas na empresa capitalista falida do que uma trajetória de inovação na forma de organizar e coordenar os processos de trabalho dos produtores. A participação é mais formal do que propriamente um exercício coletivo do poder autônomo e uma participação autogestora. $\mathrm{Na}$ empresa capitalista, a hierarquia já começa pela subsunção real do trabalhador ao dono dos meios de produção. Essa subsunção foi superada, todavia, persiste a hierarquização entre os próprios produtores pelo poder de mando de dadas funções.

$\mathrm{Na}$ Redimcooper, há reprodução da divisão do trabalho pelas especialidades, mas foi rompido o controle hierárquico do trabalho. E não há a divisão entre proprietários e não proprietários e nem a presença de mais valia; então foi rompida a subsunção real no capital e instituída uma participação autogestora.

Um pouco diferente é na Cooperama, na qual há uma divisão espontânea do trabalho. Nela, o central é o tempo de trabalho dedicado à cooperativa, é ele quem vai atribuir maior poder decisório e de participação nos resultados do trabalho coletivo. É o valor do trabalho mediando o exercício do poder. Porém, não se constitui uma particularidade da Cooperama. Também existe nas duas outras. Se as cooperativas são geridas por seus trabalhadores e, portanto, sem a subsunção a um capitalista, o poder está com quem 
nelas labuta. Assim, diferenciam-se de unidades de capital, onde o trabalho não tem poder de gestão; muito ao contrário, o poder está com aquele que explora e subsume a capacidade de trabalho.

Pelo exposto, os trabalhadores dessas cooperativas se configuram como produtores associados e livres do capitalista patrão e da subsunção real ao capital. Eles se organizaram em grupo e passaram a constituir um coletivo e, da cooperação de diversos trabalhos parciais, deu-se a composição do trabalhador coletivo, livre da cooperação forçada pelo comprador da mercadoria força de trabalho. $\mathrm{O}$ trabalho desses produtores associados está sob uma coordenação eleita por todos e com funções de garantir a sintonia entre os diversos trabalhos parciais. Mas, a valorização do saber dos produtores diretos e a destituição do poder vertical, a ponto de ser permitida autonomia como possibilidade de criação, decisão e execução de um processo de trabalho e materialização da participação autogestora, não é realidade nas três cooperativas em estudo.

No modo de organizar um processo de trabalho, leva-se em consideração a finalidade do processo de produção, a organização do trabalho no concernente à divisão e ao controle, e o tipo de gestão. Esses elementos são comuns a todas as organizações produtivas, independentemente da trajetória ocupacional de quem as organiza. Todavia, considerando as três experiências aqui analisadas, a trajetória ocupacional interfere na definição do tipo de produção a ser desenvolvido, nas condições de aquisição dos meios de produção, na divisão e controle do trabalho e na gestão com presença da participação autogestora.

O objetivo deste trabalho foi demonstrar as influências das trajetórias ocupacionais no processo de constituição da cooperativa e a organização do trabalho cooperado e autogestor, nos aspectos da divisão e gestão do trabalho, destacando a presença da participação autogestora e o cancelamento da subsunção real do trabalho ao capital. Os resultados encontrados indicam que aqueles trabalhadores, com uma trajetória ocupacional marcada pela presença na participação do trabalhador coletivo, reproduzem a divisão do trabalho conhecido quando da relação de trabalho subsumido no capital. Porém, não é tendência a reprodução da divisão hierárquica do trabalho na sua totalidade. O que é mantida nas três experiências é a separação entre o trabalho produtivo e o trabalho administrativo. Nas três experiências, é o presidente da cooperativa que administra a unidade coletiva de trabalho, com tendência a considerar as pessoas que exercem a função de administradores aptos a assumir a função de coordenador da unidade. Apesar de em todas três haver uma direção legitimada pelo processo eleitoral, a participação no processo decisório com materialização da participação autogestora não é tendência nas três experiências.
Observou-se dimanar o desenvolvimento do trabalho coletivo com cooperação voluntária, com gestões marcadas pelo exercício do poder no coletivo dos associados. E, ainda, manifestações da preservação da união do grupo e o domínio coletivo do conhecimento sobre os avanços e dificuldades das cooperativas, com participação em todo processo de produção e dos resultados dela.

\section{Referências}

MARX, K. Capital VI - inédito de O capital. Tradução Klaus Von Puchen. São Paulo: Centauro, 2004.

O capital: crítica da economia política. Tradução de Reginaldo Sant'Anna. Rio de Janeiro: Civilização Brasileira, 2005a. (livro I. v. 1).

O capital: crítica da economia política. O processo de produção do Capital. Tradução de Reginaldo Sant'Anna. Rio de Janeiro: Civilização Brasileira, 2005b. (livro I.v. 2).

SIMÃO, V. M. Trajetórias e a organização do trabalho cooperado e autogestor. 2008. $254 \mathrm{f}$. Tese (Doutorado em Política Social)-Brasília, Universidade de Brasília, 2008.

\section{Notas}

1 Para preservar a identidade, os nomes atribuídos às cooperativas são fictícios.

2 Uma trajetória descreve a série de posições sucessivamente ocupadas por uma mesma pessoa ou grupo de pessoas, submetidas a mudanças ou a não-mudanças. A localização dos eventos, a duração da existência e a sua situação no transcurso de uma trajetória ocupacional são, normalmente, resultado das mudanças ocorridas no mundo do trabalho e das possibilidades do trabalhador de acompanhar tais mudanças, sendo ele incluído, excluído ou as duas condições ocorrendo, para uma mesma pessoa, de tempos em tempos (SIMÃO, 2008).

3 A empresa Multibrás S.A. Eletrodomésticos de Joinville, subsidiária da Whiripool Corporation, juntamente com as empresas Brastemp, Cônsul e Semer, constituem, em 2002, o Instituto Consulado da Mulher e passam a desenvolver projetos sociais e, ao mesmo tempo, têm garantida a certificação das empresas como socialmente responsáveis.

4 A Coopersul, segundo o atual assessor jurídico, não tem nenhum vínculo com a empresa anterior, a não ser o fato de estar estabelecida no mesmo local, ou seja, no terreno penhorado pelas dívidas trabalhistas. Contudo, oúnico modo de se evitar qualquer julgamento de sucessão, tanto 
trabalhista quanto tributária, é ter a falência como um marco jurídico, determinando o fim da empresa (SIMÃO, 2008). No entanto, tal fato jurídico não ocorreu.

5 Integrada a concepção de democracia participativa, são definidas algumas características da participação autogestora: o poder é exercido no coletivo dos associados; portanto, não como propriedade individual, mas sim como manifestação da preservação da união do grupo e domínio coletivo do conhecimento sobre os avanços e dificuldades da cooperativa; visão de historicidade das normas e regras, ou seja, abertura para a mudança dessas normas no decorrer da trajetória da cooperativa, desde que de comum acordo entre todos os cooperados; participação em todo o processo de produção e dos resultados dela, de modo que as pessoas atuem de comum acordo de forma cooperada; direção legitimada pelo processo eleitoral e manutenção do diálogo com a base, através de assembleias, de conselhos e de comissões de cooperados por setores; no caso de cooperativas com complexa divisão de trabalho, com inclusão de espaços de debate e interação, por meio dos quais as informações circuleme, por meio deles, as propostas de ação serão delineadas (SIMÃO, 2008).

\section{Vilma Margarete Simão}

vilmasimao@furb.br

Doutorado em Política Social pela Universidade de Brasília (UnB)

Professora e Coordenadora do Curso de Serviço Social da Universidade Regional de Blumenau (FURB)

\section{FURB - Curso de Serviço Social}

Rua Antônio da Veiga, 140

Bairro Victor Konder

Blumenau - Santa Catarina - Brasil

CEP: 89012-900 